\title{
The Author Replies to Mari Haneda
}

Roumiana Ilieva

I was very pleased to read Mari Haneda's response to my article, not simply because it comments positively on my work, but because I see Haneda's views as a useful contribution to a much-needed conversation on how to attend to culture in adult second-language classrooms at this time of reconceptualization of the place of culture in language education (Byram \& Fleming, 1998; Courchêne, 1996; Kramsch, 1993). Haneda brings hopeful possibilities into the following two facets of the culture exploration approach I advocate: language learners as ethnographers and complexity as an inherent aspect of culture. As I agree with most of Haneda's views, I comment only on aspects where I feel I may add to the ideas she presents.

Drawing on the ethnographic literature, Haneda observes that ethnographers can play various roles on the observation-participation continuum in a given context. I fully agree and would like to add that the roles student participant-observers can play in a situation, especially outside the classroom, depend very much on the access they have to a given activity. In this sense, power relations are very much a part of the participant observation process. With respect to the tasks students engage in both in observations and classroom discussions, like Haneda I feel uncomfortable with the sexist connotation of perceiving them as Adam's and Eve's tasks. I suggest that we view them as an experiential-analytical-experiential sequence, fully aware that activities cannot be clearly cut into experiential or analytical as each incorporates elements of the other.

I found Haneda's application of Vygotsky's work to culture exploration insightful in addressing the complexity of our cultural lives. With respect to whether students can contribute significantly to changing the practices in which they participate, I believe that this depends on how they position themselves, as well as on how they are positioned by other participants in these practices. Thus I perceive culture as always contested and negotiated, and an awareness of the implications of power relations in cultural practices an important aspect of the culture exploration approach.

Finally, I would like to thank Haneda for her response to my article in support of a view of culture as a process to be explored in language classrooms that I tried to advocate. I would also like to refer readers who are interested in addressing culture as a process, and not merely a product in language classrooms, to a recent book by Roberts, Byram, Barro, Jordan, and Street (2001). Despite its focus on how to apply ethnography with higher 
education foreign language students, it presents many ideas that could be pertinent in second-language and culture instruction contexts.

\section{References}

Byram, M., \& Fleming, M. (Eds.). (1998). Language learning in intercultural perspective. Cambridge, UK: Cambridge University Press.

Courchêne, R. (1996). Teaching Canadian culture: Teacher preparation. TESL Canada Journal, $13(2), 1-16$.

Kramsch, C. (1993). Context and culture in language teaching. Oxford, UK: Oxford University Press.

Roberts, C., Byram, M., Barro, A., Jordan, S., Street, \& B. (2001). Language learners as ethnographers. Clevedon, UK: Multilingual Matters. 